\title{
Postmodern Science Edification Philosophy
}

\author{
Akbar Nikkhah \\ Department of Animal Sciences, University of Zanjan, Zanjan, Iran. \\ Email: nikkhah@znu.ac.ir \\ Received July 20 ${ }^{\text {th }}$, 2011; revised August $10^{\text {th }}, 2011$; accepted August $15^{\text {th }}, 2011$.
}

\begin{abstract}
The objective is to introduce and describe a new philosophy for global science edification that will determine the extent and nature of humans' accomplishments. These will affect life quality worldwide. Science as an ultimate essence encircles theoretical and applied findings and discoveries. These can only contribute to forming a trivial core, whilst the most crucial are insightful moral surroundings. Morality is most concerned with mentorship commitments. To sustain a dense and rigid shape that progressively improves science and life quality, imagination must be complemented with harmonizing approaches. Such perceptions become an obligation as growing knowledge creates novel questions and challenges. The upper tree of science glorified with blooming branches of knowledge, particularly over the last few centuries, is predicted to undergo progressive declines in the strength of its edification foundations unless the lower tree receives most-deserving mentorship contemplations. The upper tree describes tangible science products in routin life, and the lower tree represents sustainable mentorship. Mentors must replace teachers, by definition, and commit to generating more qualified educators than themselves. Mentors are expected to welcome and manage challenges from mentees. Challenges play crucial roles in granting mentees with integrated pathways of scientific development. The resulting pictures will be eagerly prone to revisions and elaborations as mentees themselves step into the pathway. This systematic edification will strengthen science roots in mentees' minds and will uphold a sturdy science body for society. Science pictured as an integrated circle grants a prospect to envision where humans are and where not to end up. Maintaining a definitive shape for science in any major before and while enriching central cores with experimental novelties in minds and laboratories is crucial to improving man's fulfillment of time in the third millennium. Such integrities are an obligation to optimally preserve and utilize what humans have achieved thus far and continue to accomplish.
\end{abstract}

Keywords: Science, Edification, Mentorship, Philosophy, New Millennium

\section{An Introduction to Postmodern Mentorship Philosophy}

It is compelling to consider "edification" as a most realistic reason for humans to find meanings in life. The continuing emphasis on science education supports the consideration (Alberts, 2008, 2009a, 2009b, 2009c). Summing up centuries of contemplation in science and most crucially its edification, knowledge must synthetically be transformed into insights to advance progressively. This transformation represents the transition from modern to postmodern education, which enhances in influence as knowledge grows deeper. The transition from "modern science" to "postmodern science" has to occur in "edification” concepts. It is thus not necessarily concerned with time. Instead, minds carry such transformations for which time is only an observer. For this transformation to occur persistently, edification must focus on sufficiently simple but sophisticated inter-group discussions from the very beginning in elementary schools. There has always been a belief that more junior students are too young for certain life lessens received by the more senior peers. Such erroneous practices considerably delay students' consciousness to grasp their powerful thought nature and benefit the community in multiple aspects. Science educators must gain distinction in persuading professional confrontational and provoking opinion and view exchange among students and trainees. Prevailing silence on students' part and one-way teaching should be discouraged and minimized. Such approaches will allow mentees to envision much earlier what educators or mentors have realized later in life, thus offering mentees enormous potential to visualize beyond mentors' images.

By science definition, mentors are to replace pure instructors, and to vastly welcome and manage challenges from mentees. Challenges play crucial roles in introducing mentees with integrated pathways of scientific development. The resulting pictures will be eagerly prone to future revisions and elaborations as mentees themselves step into such pathways. This systematic and circular edification will strengthen science roots in mentees' minds and will uphold a sturdy body for science.

\section{Science Edification as a Postmodern Superpower}

The proposed feature simply resembles a tree with its roots, base, major and minor branches, leaves, and fruits the foremost. That is a global perception for science without which all other theoretical and experimental accomplishments will not gain lasting power and fruitfulness. The upper tree of science glorified with blooming branches of knowledge is predicted to undergo progressive declines in the strength of its edification foundations unless the lower tree receives most-deserving mentorship contemplations. The upper tree describes tangible science products in routin life, and the lower tree represents sustainable mentorship. Therefore, the more fundamental and powerful the lower tree, the higher life quality. What humans have achieved and built thus far, and particularly over the last 4 centuries, now we begin to realize that concern mostly the up- 
per tree. With uncovering and discovering more quantitative and qualitative science, the lower tree must be fortified for more blooming and productive upcoming generations. The lower tree is essentially concerned with moral commitments to training more qualified upcoming mentors/scientists than those of past and present times. This is an obligation for creating an integrated form for global science that maintains its evolving trend.

\section{Science and Morality: Elusive Patterns}

Although known and discussed for centuries, morality is an elusive concept that has rarely, if at all, been simply defined in very few global terms. Morality should essentially be incessantly refined and interpreted, such that science can capaciously realize its prevailing role in improving man's life. With the imaginable tree of science growing as a circle, for instance, theoretical and applied findings and discoveries can only contribute to its core or the insignificant central point. What shape morality are the surroundings of the core or the essentialities maintaining an integrated circular shape. Without such dense environs, the circle would loose its essence and integrity, thus becoming a straight line. However, even with the central hub being even as infinitesimal as an invisible point, the circle will still be a circle. These concepts implement a phenomenon that science is entirely meaningless without its moral elements, even if filled with expanded experimental novelties.

\section{Structuring a New Millennium Science Edification}

Edification for scientists and mentors in the new millennium on must accordingly incorporate describing moral responsibilities alongside technical and imaginary skills. Influential thought authorities of the $20^{\text {th }}$ century (e.g., Albert Einstein) had exemplified that how imagination outshine knowledge. Now, we tend to globally comprehend that while is knowledge always relatively uncovered, imagination is merely the beginning to furthering knowledge. Thus, to form and sustain a dense and rigid shape that progressively improves man's life, knowledge and imagination must be complemented with harmonizing approaches. Such much needed perceptions become an obligation as the growing knowledge gives rise to novel questions and challenges.

Science pictured as an integrated circle grants a prospect to envision where we are and where we must or must not end up. Maintaining a definitive shape for science in any major before and while enriching central cores with experimental novelties in minds and laboratories is crucial to improving man's fulfillment of time. It is only with such a representation that science can continue to impress upon us constructively enough to deserve investing and dedicating time, finance, and brain work. Science edification with definitive imaginative moral shapes versus science with no mindful illustrations separates "post- modern" versus “modern” mentorship philosophy. Modern education is concerned with time and non-time compensations and locations while postmodern edification represents moral commitments that are not described by and limited to time and space. The education modernity describes teaching philosophies whilst the edification postmodernity represents mentoring obligations. The modern education produces data, publications, technologies and laboratories while the postmodern edification generates more qualified mentors who can give rise to higher quality upcoming mentors in addition to such science products. All in all, the modern philosophy improves the current science at the expense of the future mentorship while the postmodern edification empowers mentorship to establish improvements in science of the past, present, and future.

\section{Implications}

Making the most fruitful edification policies necessitates conceptual appreciation of the moral constituents of science. Science does possess a rigid form with theoretical and applied findings and discoveries only contributing to its trivial core. Crucially, the most vital elements are insightful moral surroundings. Morality is most concerned with mentorship commitments. To sustain a dense and rigid shape that progressively improves science and life quality, imagination should be complemented with harmonizing approaches. Such perceptions become an obligation as the growing knowledge creates novel questions and challenges. The upper tree of science glorified with blooming branches of knowledge is predicted to undergo progressive declines in the strength of its edification foundations unless the lower tree hosts deserving mentorship contemplations. The lower tree is essentially concerned with moral commitments to training more qualified upcoming mentors than those of present and past. The more fundamental and powerful the lower tree, the higher life quality. The vision is an ultimate and simple pathway for humans to move onward in the science edification philosophy of the new millennium.

\section{Acknowledgements}

The author is grateful to the nature and environment for inspiring contemplations for improving global science edification.

\section{References}

Alberts, B. (2008). Considering science education. Science, 319, 1589. doi:10.1126/science. 1157518

Alberts, B. (2009a). Making a science of education. Science, 323, 15. doi:10.1126/science.1169941

Alberts, B. (2009b). Redefining science education. Science, 323, 437. doi:10.1126/science.1170933

Alberts, B. (2009c). Science for science. Science, 324, 13. doi:0.1126/science.1174131 